\title{
Cannabinoid Regulation of Acute and Anticipatory Nausea
}

\author{
Erin M. Rock, Martin A. Sticht, ${ }^{2}$ Cheryl L. Limebeer ${ }^{1}$ and Linda A. Parker ${ }^{1, *}$
}

\begin{abstract}
Chemotherapy-induced nausea is one of the most distressing symptoms reported by patients undergoing treatment, and even with the introduction of newer antiemetics such as ondansetron and aprepitant, nausea remains problematic in the clinic. Indeed, when acute nausea is not properly managed, the cues of the clinic can become associated with this distressing symptom resulting in anticipatory nausea for which no effective treatments are available. Clinical trials exploring the potential of exogenous or endogenous cannabinoids to reduce chemotherapy-induced nausea are sparse; therefore, we must rely on the data from pre-clinical rat models of nausea. In this review, we explore the human and pre-clinical animal literature examining the potential for exogenous and endogenous cannabinoid treatments to regulate chemotherapy-induced nausea. The preclinical evidence points to a compelling need to evaluate the antinausea potential of cannabidiol, cannabidiolic acid, and treatments that boost the functioning of the endocannabinoid system in human clinical trials.
\end{abstract}

Key words: 2-arachidonoylglycerol; acute nausea; anandamide; anticipatory nausea; $\mathrm{CB}_{1}$ receptor; conditioned gaping; endocannabinoid

\section{Introduction}

For more than 5000 years, cannabis has been utilized as a medicine (see Ref. ${ }^{1}$ ), including for the treatment of nausea and vomiting. In response to their inability to manage patients' chemotherapy-induced nausea and vomiting with conventional antiemetics, oncologists began to evaluate the antiemetic properties of cannabis in the late 1970s, following anecdotal reports of smoked cannabis alleviating chemotherapy-induced nausea and vomiting. In addition, the synthetic cannabinoid agonists, nabilone $\left(\right.$ Cesamet $\left.^{\circledR}\right)$ and dronabinol (Marinol ${ }^{\mathbb{B}}$ ), were subsequently evaluated and approved for their antiemetic and antinausea properties in chemotherapy patients. ${ }^{2}$

Currently, vomiting is relatively well managed in the clinic since the advent of the 5-hydroxytryptamine 3 $\left(5-\mathrm{HT}_{3}\right)$ receptor antagonists (such as ondansetron) and the neurokinin-1 (NK-1) receptor antagonists (such as aprepitant) ${ }^{3}$; however, nausea and anticipatory nausea (a conditioned response through which simply returning to the treatment clinic causes patients to feel nauseous as a result of their association between the contextual cues of the clinic and the nausea they experience from treatment) are still not properly managed. ${ }^{3}$ Nausea remains as one of the most distressing symptoms experienced by cancer patients undergoing chemotherapy treatment, ${ }^{4}$ highlighting the need for alternative pharmacotherapies to be explored.

Pre-clinical animal models of nausea are necessary to evaluate putative antinausea compounds. One such selective and reliable rodent model is nausea-induced conditioned gaping. Although rodents are incapable of vomiting, they display conditioned gaping reactions in response to a flavor previously paired with an illnessinducing agent such as lithium chloride $(\mathrm{LiCl}) .^{5}$ They also avoid drinking this flavor as a measure of taste

\footnotetext{
${ }^{1}$ Department of Psychology and Collaborative Neuroscience Graduate Program, University of Guelph, Guelph, Canada.

${ }^{2}$ Department of Physiology and Pharmacology, Hotchkiss Brain Institute, University of Calgary, Calgary, Canada.

*Address correspondence to: Linda A. Parker, PhD, Department of Psychology and Collaborative Neuroscience Graduate Program, University of Guelph, 50 Stone Road East, Guelph, ON N1G2W1, Canada, E-mail: parkerl@uoguelph.ca

(c) Erin M. Rock et al. 2016; Published by Mary Ann Liebert, Inc. This Open Access article is distributed under the terms of the Creative Commons License (http://creativecommons.org/licenses/by/4.0), which permits unrestricted use, distribution, and reproduction in any medium, provided the original work is properly credited.
} 
avoidance. However, conditioned gaping reactions are indicative of nausea in rodents, because, unlike taste avoidance, only emetic drugs produce conditioned gaping in rats, and antiemetic treatments (including cannabinoids) block conditioned gaping. ${ }^{6}$ Rats avoid drinking a flavor paired even with a rewarding drug. ${ }^{6}$

\section{Cannabinoids in Human Patients}

Exogenous cannabinoids

and chemotherapy-induced acute nausea

Delta-9-tetrahydrocannabinol (THC), the major psychoactive component of cannabis, ${ }^{7,8}$ is a high-affinity agonist for both the cannabinoid $1\left(\mathrm{CB}_{1}\right)$ and cannabinoid $2\left(\mathrm{CB}_{2}\right)$ receptors and it has been shown to be effective in reducing chemotherapy-induced vomiting ${ }^{9}$ and/or nausea ${ }^{10-20}$ when smoked or orally administered.

Dronabinol (Marinol), an orally administered synthetic THC, has been shown to be effective in reducing chemotherapy-induced nausea and/or vomiting. ${ }^{21-23}$ In 1985, nabilone (Cesamet), another orally administered synthetic THC, was approved for nausea and vomiting only in patients who were unresponsive to conventional treatments. Nabilone has also been shown to reduce chemotherapy-induced nausea and/ or vomiting. ${ }^{24-38}$ Please refer to Table 1 for more specific details of these findings. These findings highlight the potential of $\mathrm{CB}_{1}$ receptor agonism to reduce chemotherapy-induced nausea and/or vomiting, over that of classic antiemetic treatments.

Most recently, the oromucosal cannabis-based medicine, Sativex ${ }^{\circledR}$ (1:1, THC:cannabidiol [CBD]), when combined with the standard treatment of a $5-\mathrm{HT}_{3}$ antagonist and a corticosteroid, reduced delayed nausea (and vomiting). ${ }^{39}$ Because Sativex contains both THC and CBD, it is unknown which compound (or both) contributed to its antinausea effects. Moreover, recent findings in our laboratory indicate that subthreshold doses of THC and cannabidiolic acid (CBDA), the acidic precursor of CBD, when combined, effectively reduce acute nausea and anticipatory nausea in rats $^{40}$; however, we have not investigated whether these effects are mediated by the action of THC at the $\mathrm{CB}_{1}$ receptor, CBDA at the $5-\mathrm{HT}_{1 \mathrm{~A}}$ receptor, ${ }^{41}$ or both.

These findings highlight the therapeutic potential of exogenously administered cannabinoids such as THC to reduce chemotherapy-induced nausea. It is important to note here, the unique ability of cannabinoids, to effectively manage nausea, a symptom that current antiemetic treatments cannot control.

\section{Endocannabinoid levels during the experience}

\section{of nausea in humans}

To date, there have been no published clinical trials investigating whether endocannabinoid manipulations (such as increased action of anandamide [AEA] and 2-arachidonylglyercol [2-AG] through enzyme inhibition of fatty acid amide hydrolase [FAAH] or monoacylglycerol lipase [MAGL]) reduce nausea; however, changes in endocannabinoid levels have been measured due to nausea-inducing manipulations. For example, decreases in AEA levels have been reported with administration of the anesthesia sevoflurane, which results in postoperative nausea. ${ }^{42}$ In addition, reduced levels of AEA and 2-AG have been shown in those experiencing motion sickness. ${ }^{43}$ Therefore, it seems that endogenous cannabinoids may be important neuromodulators involved in the experience of nausea, with decreased levels of AEA and/or 2-AG evident with nausea-inducing manipulations. Further research needs to clarify how the endogenous cannabinoid system is involved in the experience of nausea, and more specifically, how manipulations of this system could attenuate chemotherapy-induced nausea.

\section{Exogenous cannabinoids}

and chemotherapy-induced anticipatory nausea

Anticipatory nausea is a conditional association between the chemotherapy clinic cues and the nausea-inducing chemotherapeutic treatment such that patients experience nausea upon returning to the clinic where illnessinducing treatment was administered. ${ }^{44}$ Anticipatory nausea develops in $25-59 \%$ of chemotherapy patients, ${ }^{44-51}$ if acute nausea has not been properly managed. Once established, anticipatory nausea is refractive to treatment with the classic $5-\mathrm{HT}_{3}$ receptor antagonists such as ondansetron, ${ }^{4,52-54}$ and patients are currently prescribed sedating antianxiety drugs (benzodiazepines) ${ }^{55,56}$ Clearly, there is a great need for alternative therapeutics for anticipatory nausea as current medicines are insufficient.

In the only published clinical trial to date assessing cannabinoids and anticipatory nausea, Lane et al. ${ }^{22}$ showed that dronabinol was ineffective in reducing anticipatory nausea, but it is important to note that $86 \%$ of the patients included in the study were being given highly emetogenic chemotherapeutic treatments. Although dronabinol may not be as effective for anticipatory nausea resulting from highly emetogenic agents, it may be effective in less emetogenic chemotherapy regimens. 


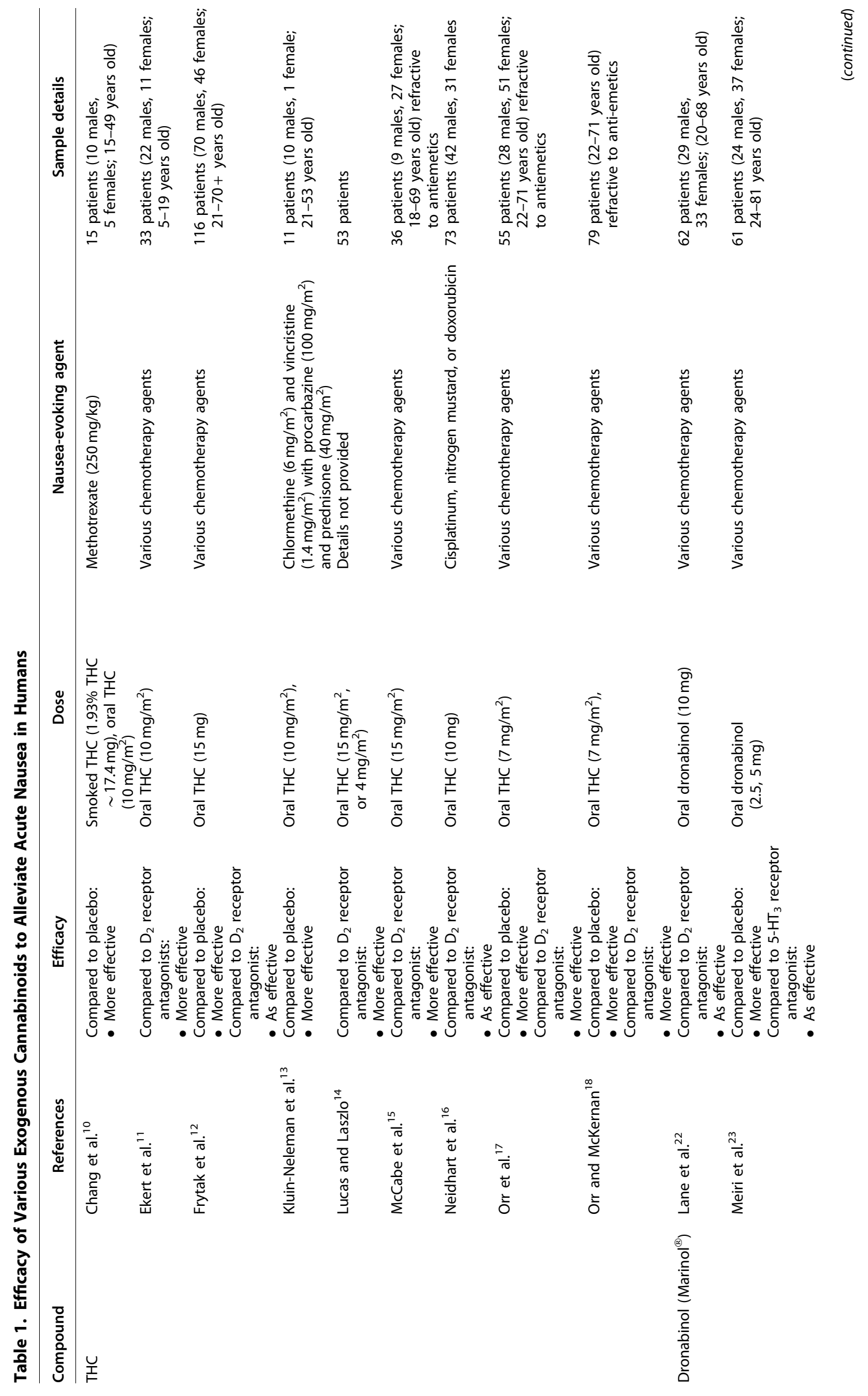




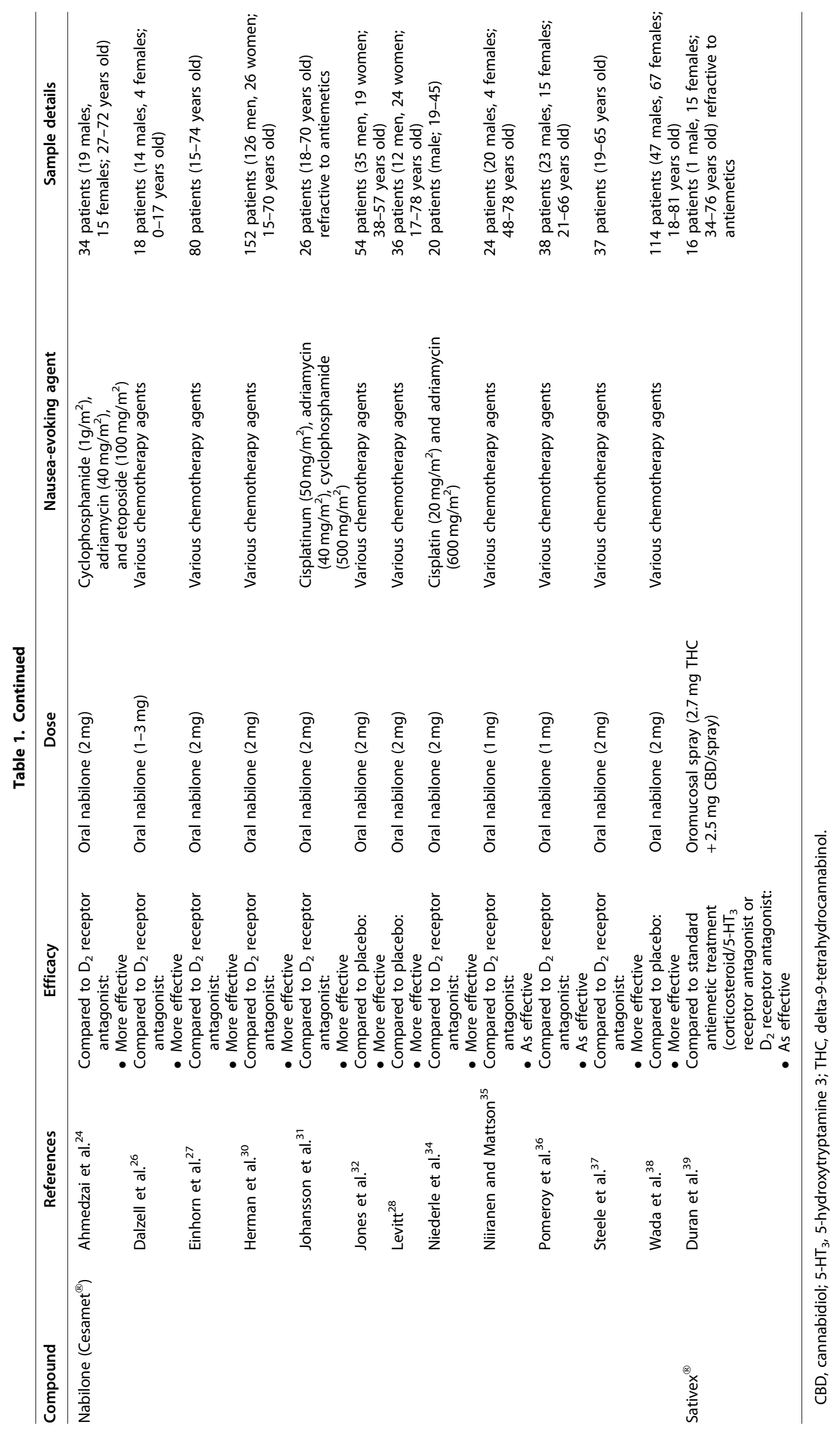


As proper management of acute nausea is the best prevention for the development of anticipatory nausea, the efficacy of THC and its synthetic derivatives in reducing acute nausea (as discussed in the section "Exogenous cannabinoids and chemotherapy-induced acute nausea") should reduce the risk of anticipatory nausea developing. Clinical trials are necessary to evaluate THC, as well as other phytocannabinoids such as $\mathrm{CBD}$, for their ability to reduce acute and/or anticipatory nausea, especially in comparison to the current first-line treatment $\left(5-\mathrm{HT}_{3}\right.$ receptor antagonist/dexamethasone/NK-1 receptor antagonist).

\section{Endogenous cannabinoids}

and chemotherapy-induced anticipatory nausea

Cannabinoid compounds are effective in reducing acute nausea in human patients (as discussed in the section "Exogenous cannabinoids and chemotherapyinduced acute nausea") and anticipatory nausea in animal models (as discussed in the section "Exogenous cannabinoids reduce anticipatory nausea in rats"), but no published clinical trials have evaluated enzyme inhibitors in anticipatory nausea patients. Such investigations have relied solely on animal models, highlighting the need for clinical trials.

\section{Cannabinoids in Animal Models of Nausea}

Considerable evidence implicates the endocannabinoid system in the regulation of nausea in the animal model of conditioned gaping reactions in rats. ${ }^{57}$ Here, we review the experimental pre-clinical evidence for the potential of cannabinoids and manipulation of the endocannabinoid system to reduce both acute ${ }^{57}$ and anticipatory nausea ${ }^{58}$ based upon the conditioned gaping models. Please refer to Table 2 for more specific details of these findings.

\section{Exogenous cannabinoids reduce acute nausea-induced conditioned gaping} THC attenuates the establishment of acute nauseainduced conditioned gaping induced by the chemotherapy drug cyclophosphamide, ${ }^{59}$ as well as with $\mathrm{LiCl},{ }^{60,61}$

Table 2. Efficacy of Various Exogenous and Endogenous Cannabinoids to Alleviate Nausea-Induced Conditioned Gaping and Contextually Elicited Conditioned Gaping in Rats

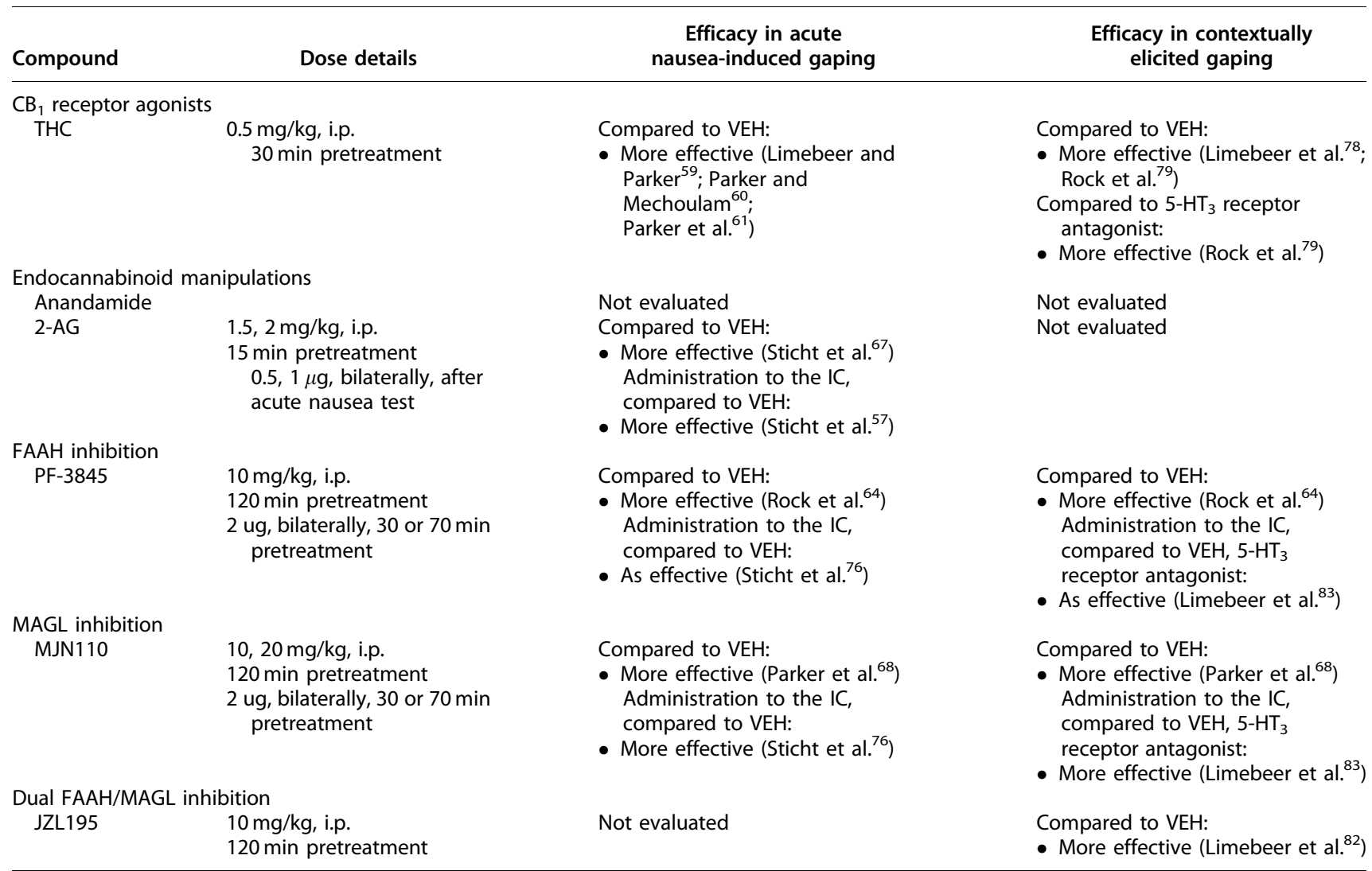

$\mathrm{CB}_{1}$, cannabinoid 1; 2-AG, 2-arachidonylglyercol; FAAH, fatty acid amide hydrolase; IC, insular cortex; MAGL, monoacylglycerol lipase. 
through a $\mathrm{CB}_{1}$ receptor-mediated effect. Thus, as demonstrated in humans, THC (through $\mathrm{CB}_{1}$ receptor agonism) has an antinausea effect in the rat conditioned gaping model (acute nausea).

It is interesting to note that two nonpsychoactive cannabinoids found in cannabis, $\mathrm{CBD}^{60}$ and its precursor $\mathrm{CBDA},{ }^{41}$ also interfere with acute nausea-induced conditioned gaping in rats without impairing the locomotor activity. CBDA was 1000 times more potent than CBD in reducing acute nausea. ${ }^{62}$ Unlike THC, however, the antinausea effect of $\mathrm{CBD}^{63}$ and $\mathrm{CBDA}^{41}$ was mediated by agonism of $5-\mathrm{HT}_{1 \mathrm{~A}}$ receptors, not $\mathrm{CB}_{1}$ receptors. Furthermore, subthreshold doses of CBDA potentiated the antinausea effect of the $5-\mathrm{HT}_{3}$ receptor antagonist, ondansetron. ${ }^{62}$ These findings suggest that $\mathrm{CBDA}$, in particular, may be a highly effective treatment for acute nausea alone or in combination with conventional treatments, although it has not yet been evaluated in clinical trials.

\section{Endogenous cannabinoids reduce acute} nausea-induced conditioned gaping

Recent studies in our laboratory have investigated the role of the endogenous cannabinoid system in acute nausea-induced conditioned gaping, utilizing enzyme inhibitors that increase AEA and 2-AG levels (through inhibition of FAAH or MAGL, respectively). PF-3845, a novel FAAH inhibitor, reduces acute nausea-induced conditioned gaping; however, this effect was reversed by a peroxisome proliferatoractivated receptor alpha $(\mathrm{PPAR} \alpha)$ receptor antagonist, not a $\mathrm{CB}_{1}$ receptor antagonist. ${ }^{64}$ It is likely that this antinausea effect is due to increases in oleoylethanolamide (OEA) and palmitoylethanolamide (PEA) following PF-3845 administration. ${ }^{65}$ Further investigation of the effect of fatty acids other than AEA on acute nausea is thus warranted. However, AEA may also be involved in the antinausea effect of FAAH inhibition, because the FAAH inhibitor, URB597, potentiated the antinausea effect of systemic AEA administration and this effect was reversed by $\mathrm{CB}_{1}$ receptor antagonism. ${ }^{66}$

Exogenous 2-AG administration (which is rapidly deactivated by MAGL) reduces acute nausea-induced conditioned gaping. ${ }^{67}$ MJN110, a MAGL inhibitor, also reduces acute nausea-induced conditioned gaping, a $\mathrm{CB}_{1}$ receptor-mediated effect. ${ }^{68}$ The aforementioned results, pertaining to systemic administration of enzyme inhibitors, suggest a role of the endogenous cannabinoid system in the suppression of nausea, but the specific brain region(s) critical for nausea are still not completely clear.

A brain region of interest for nausea is the interoceptive insular cortex (IC), an area shown to be involved in nausea, ${ }^{69}$ as stimulation of the $\mathrm{IC}^{70-72}$ and functional neuroimaging studies in humans ${ }^{73,74}$ pinpoint the IC as a critical region for nausea.

Our laboratory has begun to investigate how the endogenous cannabinoid system mediates nausea, with a specific focus on the rat interoceptive IC. Indeed, administration of the synthetic cannabinoid, HU-210, into the interoceptive IC reduces conditioned gaping through a $\mathrm{CB}_{1}$ receptor-mediated effect. ${ }^{75}$ Furthermore, administration of $2-A G$ to the interoceptive IC reduces conditioned gaping, ${ }^{57}$ and administration of the MAGL inhibitor MJN110 into the interoceptive IC (but not the FAAH inhibitors URB597 or PF3845) reduces conditioned gaping, a $\mathrm{CB}_{1}$ receptormediated effect. ${ }^{76}$ These results suggest that the effects of the endocannabinoid system during an experience of acute nausea may be mediated by $2-\mathrm{AG}$ (and not AEA) in the interoceptive IC.

\section{Exogenous cannabinoids reduce anticipatory} nausea in rats

In addition to displaying conditioned gaping to a nausea-paired flavor, rats also display conditioned gaping when returned to a nausea-paired context; a phenomenon analogous to human anticipatory nausea. ${ }^{77}$ Furthermore, much like with human anticipatory nausea, ondansetron does not reduce contextually elicited conditioned gaping in rats. ${ }^{78,79}$ Also, similar to human anticipatory nausea, administration of benzodiazepine does reduce contextually elicited conditioned gaping in rats, but also impairs locomotor activity. ${ }^{79}$ In contrast, low doses of THC reduce contextually elicited gaping in the absence of impaired locomotion, ${ }^{78,79}$ indicating that THC may be a superior therapeutic, over sedating benzodiazepines, in treating anticipatory nausea.

As with acute nausea, both $\mathrm{CBD}^{80}$ and $\mathrm{CBDA}^{41,79}$ reduce anticipatory nausea in this pre-clinical model by a $5-\mathrm{HT}_{1 \mathrm{~A}}$ receptor mechanism of action, with CBDA about 1000 times more potent than CBD. ${ }^{79} \mathrm{Nei}-$ ther $\mathrm{CBD}$ nor CBDA interfered with motor activity. Given that these compounds are nonpsychoactive, future clinical trials with human patients are gravely needed as there are currently no specific treatments for anticipatory nausea in humans. 


\section{Endogenous cannabinoids reduce anticipatory}

nausea in rats

The endogenous cannabinoid system has also been implicated in the control of anticipatory nausea (for review). ${ }^{81}$ The FAAH inhibitors URB597 or PF-3845 reduce contextually elicited conditioned gaping; unlike acute nausea, the antinausea effect of FAAH inhibition on anticipatory nausea was reversed by a $\mathrm{CB}_{1}$ receptor antagonist, ${ }^{64,80}$ presumably through AEA elevation. The MAGL inhibitor, MJN110, also reduces contextually elicited gaping in rats, $\mathrm{CB}_{1}$ receptor-mediated effect. $^{68}$ Finally, dual FAAH-MAGL inhibition with JZL195 reduces contextually elicited gaping by elevated $\mathrm{AEA}, \mathrm{PEA}$, and $\mathrm{OEA},{ }^{82} \mathrm{a} \mathrm{CB}_{1}$ receptor-mediated effect. Recent findings in our laboratory indicate that infusion of the MAGL inhibitor, MJN110 (but not the FAAH inhibitor PF-3845 nor ondansetron), into the interoceptive IC suppressed contextually elicited conditioned gaping, a $\mathrm{CB}_{1}$ receptor-mediated effect. ${ }^{83}$ These results suggest that the interoceptive IC may be a critical region for $\mathrm{AN}$ (in addition to acute nausea), mediated by $2-A G$ activity at the $\mathrm{CB}_{1}$ receptor.

\section{Conclusions}

The endocannabinoid system clearly plays an important role in the regulation of nausea. The pre-clinical findings suggest that $\mathrm{CB}_{1}$ receptor agonists, as well as FAAH and MAGL inhibitors, which elevate levels of AEA and 2-AG, respectively, reduce acute nausea and anticipatory nausea. As well, by a noncannabinoid mechanism of action, both $\mathrm{CBD}$ and CBDA are highly effective antinausea treatments in these animal models without producing sedation or psychoactive effects. Nausea remains an elusive, difficult to control symptom in human chemotherapy patients and there are currently no selective treatments for anticipatory nausea. Clinical trials with FAAH inhibitors, MAGL inhibitors, CBD, and CBDA are warranted to improve the quality of life of patients undergoing cancer treatment by reducing the side effects of nausea and anticipatory nausea when it develops.

\section{Acknowledgments}

The authors gratefully acknowledge research support from the Natural Sciences and Engineering Research Council of Canada (NSERC: 92057) to LAP and Canadian Institutes of Health Research (CIHR: 334086) to LAP and Keith Sharkey.

\section{Author Disclosure Statement}

No competing financial interests exist.

\section{References}

1. Iversen LL. The science of marijuana. 2nd ed. Oxford University Press: New York, NY, 2008

2. Pertwee RG. Emerging strategies for exploiting cannabinoid receptor agonists as medicines. Br J Pharmacol. 2009;156:397-411.

3. Hickok JT, Roscoe JA, Morrow GR, et al. Nausea and emesis remain significant problems of chemotherapy despite prophylaxis with 5-hydroxytryptamine-3 antiemetics: a university of rochester james $P$. wilmot cancer center community clinical oncology program study of 360 cancer patients treated in the community. Cancer. 2003;97:2880-2886.

4. Aapro MS, Molassiotis A, Olver I. Anticipatory nausea and vomiting. Support Care Cancer. 2005;13:117-121.

5. Grill HJ, Norgren R. The taste reactivity test. I. Mimetic responses to gustatory stimuli in neurologically normal rats. Brain Res. 1978;143:263-279.

6. Parker LA. Conditioned flavor avoidance and conditioned gaping: rat models of conditioned nausea. Eur J Pharmacol. 2014;722:122-133.

7. Gaoni Y, Mechoulam R. Isolation, structure, and partial synthesis of an active constituent of hashish. J Am Chem Soc. 1964;86;1646-1647.

8. Mechoulam R, Shani A, Edery $H$, et al. Chemical basis of hashish activity. Science. 1970;169:611-612.

9. Sallan SE, Zinberg NE, Frei E. Antiemetic effect of delta-9tetrahydrocannabinol in patients receiving cancer chemotherapy. $\mathrm{N}$ Engl J Med. 1975;293:795-797.

10. Chang $A E$, Shiling DJ, Stillman $R C$, et al. Delata-9-tetrahydrocannabinol as an antiemetic in cancer patients receiving high-dose methotrexate. A prospective, randomized evaluation. Ann Intern Med. 1979;91:819-824.

11. Ekert $\mathrm{H}$, Waters KD, Jurk IH, et al. Amelioration of cancer chemotherapyinduced nausea and vomiting by delta-9-tetrahydrocannabinol. Med J Aust. 1979;2:657-659.

12. Frytak S, Moertel CG, O'Fallon JR, et al. Delta-9-tetrahydrocannabinol as an antiemetic for patients receving cancer chemotherapy. A comparison with prochlorperazine and a placebo. Ann Intern Med. 1979;91:825-830.

13. Kluin-Neleman JC, Neleman FA, Meuwissen OJ, et al. Delta 9tetrahydrocannabinol (THC) as an antiemetic in patients treated with cancerchemotherapy; a double-blind cross-over trial against placebo. Vet Hum Toxicol. 1979;21:338-340.

14. Lucas VS, Laszlo J. delta 9-Tetrahydrocannabinol for refractory vomiting induced by cancer chemotherapy. JAMA. 1980;243:1241-1243.

15. McCabe M, Smith FP, Macdonald JS, et al. Efficacy of tetrahydrocannabinol in patients refractory to standard antiemetic therapy. Invest New Drugs. 1988;6:243-246.

16. Neidhart JA, Gagen MM, WIlson HE, et al. Comparative trial of the antiemetic effects of THC and haloperidol. J Clin Pharmacol. 1981;21:38S-42S.

17. Orr LE, McKernan JF, Bloome B. Antiemetic effect of tetrahydrocannabinol. Compared with placebo and prochlorperazine in chemotherapyassociated nausea and emesis. Arch Intern Med. 1980;140:1431-1433.

18. Orr LE, McKernan JF. Antiemetic effect of delta 9-tetrahydrocannabinol in chemotherapy-associated nausea and emesis as compared to placebo and compazine. J Clin Pharmacol. 1981;21:76S-80S.

19. Sweet DL, Miller NJ, Weddington W, et al. Delta 9-tetrahydrocannabinol as an antiemetic for patients receiving cancer chemotherapy. A pilot study. J Clin Pharmacol. 1981;21:70S-75S.

20. Vinciguerra $V$, Moore T, Brennan E. Inhalation marijuana as an antiemetic for cancer chemotherapy. N Y State J Med. 1988;88:525-527.

21. Elder J, Knoderer HM. Characterization of dronabinol usage in a pediatric oncology population. J Pediatr Pharmcol. 2015;26:462-467.

22. Lane $\mathrm{M}$, Vogel $\mathrm{CL}$, Ferguson J, et al. Dronabinol and prochlorperazine in combination for treatment of cancer chemotherapy-induced nausea and vomiting. J Pain Symptom Manage. 1991;6:352-359.

23. Meiri $E$, Jhangiani $H$, Vredenburgh JJ, et al. Efficacy of dronabinol alone and in combination with ondansetron versus ondansetron alone for delayed chemotherapy-induced nausea and vomiting. Curr Med Res Opin. 2007;23:533-543.

24. Ahmedzai S, Carlyle DL, Calder IT, et al. Anti-emetic efficacy and toxicity of nabilone, a synthetic cannabinoid, in lung cancer chemotherapy. Br J Cancer. 1983;48:657-663.

25. Chan HS, Correia JA, MacLeod SM. Nabilone versus prochlorperazine for control of cancer chemotherapy-induced emesis in children: a doubleblind, crossover trial. Pediatrics. 1987;79:946-952.

26. Dalzell AM, Bartlett $H$, Lilleyman JS. Nabilone: an alternative antiemetic for cancer chemotherapy. Arch Dis Child. 1986;61:502-505. 
27. Einhorn LH, Nagy C, Fumas B, et al. Nabilone: an effective antiemetic in patients receiving cancer chemotherapy. J Clin Pharmacol. 1981;21: 64S-69S.

28. Levitt M. Nabilone vs. placebo in the treatment of chemotherapy-induced nausea and vomiting in cancer patients. Cancer Treat Rev. 1982;9:49-53.

29. Herman TS, Jones SE, Dean J. Nabilone: a potent antiemetic cannabinol with minimal euphoria. Biomedicine. 1977;27:331-334.

30. Herman TS, Einhorn LH, Jones SE, et al. Superiority of nabilone over prochlorperazine as an antiemetic in patients receiving cancer chemotherapy. N Engl J Med. 1979;300:1295-1297.

31. Johansson R, Kilkku P, Groenroos M. A double-blind, controlled trial of nabilone vs. prochlorperazine for refractory emesis induced by cancer chemotherapy. Cancer Treat Rev. 1982;9B:25-33.

32. Jones SE, Durant JR, Greco A, et al. A multi-institutional phase III study of nabilone vs. placebo in chemotherapy-induced nausea and vomiting. Cancer Treat Rev. 1982;9B:45-48.

33. Niamatali C, Fallon SD, Egan EL. Nabilone in the management of prochlorperazine resistant cancer chemotherapy induced emesis. Ir Med J. 1984;77:276-277.

34. Niederle N, Schütte J, Schmidt CG. Crossover comparison of the antiemetic efficacy of nabilone and alizapride in patients with nonseminomatous testicular cancer receiving cisplatin therapy. Klin Wochenschr 1986;64:362-365.

35. Niiranen A, Mattson K. A cross-over comparison of nabilone and prochlorperazine for emesis induced by cancer chemotherapy. Am J Clin Oncol. 1985;8:336-340.

36. Pomeroy M, Fennelly JJ, Towers M. Prospective randomized double-blind trial of nabilone versus domperidone in the treatment of cytotoxicinduced emesis. Cancer Chemother Pharmacol. 1986;17:285-288.

37. Steele N, Gralla RJ, Braun DW Jr, et al. Double-blind comparison of the antiemetic effects of nabilone and prochlorperazine on chemotherapyinduced emesis. Cancer Treat Rep. 1980;64:219-224.

38. Wada JK, Bofdon DL, Gunnell JC, et al. Double-blind, randomized, crossover trial of nabilone vs. placebo in cancer chemotherapy. Cancer Treat Rev. 1982;9B:39-44.

39. Duran $M$, Pérez $E$, Abanades $S$, et al. Preliminary efficacy and safety of an oromucosal standardized cannabis extract in chemotherapy-induced nausea and vomiting. Br J Clin Pharmacol. 2010;70:656-663.

40. Rock EM, Limebeer CL, Parker LA. Effect of combined doses of $\Delta$ (9)tetrahydrocannabinol (THC) and cannabidiolic acid (CBDA) on acute and anticipatory nausea using rat (Sprague-Dawley) models of conditioned gaping. Psychopharmacology (Berl). 2015;232:4445-4454.

41. Bolognini $D$, Rock EM, Cluny NL, et al. Cannabidiolic acid prevents vomiting in Suncus murinus and nausea-induced behaviour in rats by enhancing 5-HT1A receptor activation. Br J Pharmacol. 2013;168:14561470 .

42. Schelling G, Hauer D, Azad SC, et al. Effects of general anesthesia on anandamide blood levels in humans. Anesthesiology. 2006;104:273-277.

43. Choukèr A, Kaufmann I, Kreth $S$, et al. Motion sickness, stress and the endocannabinoid system. PLoS One. 2010;5:1-7.

44. Nesse RM, Carli T, Curtis GC, et al. Pretreatment nausea in cancer chemotherapy: a conditioned response? Psychosom Med. 1980;42:33-36.

45. Akechi T, Okuyama T, Endo, C, et al. Anticipatory nausea among ambulatory cancer patients undergoing chemotherapy: prevalence, associated factors, and impact on quality of life. Cancer Sci. 2010;101: 2596-2600.

46. Bovbjerg DH, Redd $\mathrm{WH}$, Jacobsen $\mathrm{PB}$, et al. An experimental analysis of classically conditioned nausea during cancer chemotherapy. Psychosom Med. 1992;54:623-637.

47. Hickok JT, Roscoe JA, Morrow GR. The role of patients' expectations in the development of anticipatory nausea related to chemotherapy for cancer. J Pain Symptom Manage. 2001;22:843-850.

48. Stockhorst U, Klosterhalfen S, Klosterhalfen W, et al. Anticipatory nausea in cancer patients receiving chemotherapy: classical conditioning etiology and therapeutical implications. Integr Physiol Behav Sci. 1993;28:177-181.

49. Tyc VL, Mulhern RK, Bieberich AA. Anticipatory nausea and vomiting in pediatric cancer patients: an analysis of conditioning and coping variables. J Dev Behav Pediatr. 1997;18:27-33.

50. Watson M, McCarron J, Law M. Anticipatory nausea and emesis, and psychological morbidity: assessment of prevalence among out-patients on mild to moderate chemotherapy regimens. Br J Cancer. 1992;66:862-866.
51. Zachariae R, Paulsen K, Mehlsen M, et al. Anticipatory nausea: the role of individual differences related to sensory perception and autonomic reactivity. Ann Behav Med. 2007;33:69-79.

52. Foubert J, Vaessen G. Nausea: the neglected symptom? Eur J Oncol Nurs. 2005;9:21-32.

53. Morrow GR, Roscoe JA, Hynes $\mathrm{HE}$, et al. Progress in reducing anticipatory nausea and vomiting: a study of community practice. Support Care Cancer. 1998;6:46-50.

54. Morrow GR, Roscoe JA, Kirshner JJ, et al. Anticipatory nausea and vomiting in the era of 5-HT3 antiemetics. Support Care Cancer. 1998;6:244-247.

55. Malik IA, Khan WA, Qazilbash M, et al. Clinical efficacy of lorazepam in prophylaxis of anticipatory, acute, and delayed nausea and vomiting in duced by high doses of cisplatin. A prospective randomized trial. Am J Clin Oncol. 1995;18:170-175.

56. Razavi D, Delvaux N, Farvacques $C$, et al. Prevention of adjustment disorders and anticipatory nausea secondary to adjuvant chemotherapy: a double-blind, placebo-controlled study assessing the usefulness of alprazolam. J Clin Oncol. 1993;11:1384-1390.

57. Sticht $M A$, Limebeer $C L$, Rafla BR, et al. Intra-visceral insular cortex 2arachidonoylglycerol, but not $\mathrm{N}$-arachidonoylethanolamide, suppresses acute nausea-induced conditioned gaping in rats. Neuroscience. 2014;286:338-344.

58. Rock EM, Limebeer CL, Parker LA. Anticipatory nausea in animal models: a review of potential novel therapeutic treatments. Exp Brain Res. 2014;232:2511-2534.

59. Limebeer CL, Parker LA. Delta-9-tetrahydrocannabinol interferes with the establishment and the expression of conditioned rejection reactions produced by cyclophosphamide: a rat model of nausea. Neuroreport 1999:10:3769-3772.

60. Parker LA, Mechoulam R. Cannabinoid agonists and antagonists modulate lithium-induced conditioned gaping in rats. Integr Physiol Behav Sci. 2003;38:133-145.

61. Parker LA, Mechoulam R, Schlievert C, et al. Effects of cannabinoids on lithium-induced conditioned rejection reactions in a rat model of nausea. Psychopharmacology (Berl). 2003;166:156-162.

62. Rock EM, Parker LA. Effect of low doses of cannabidiolic acid and ondansetron on $\mathrm{LiCl}$-induced conditioned gaping (a model of nauseainduced behaviour) in rats. Br J Pharmacol. 2013;169:685-692.

63. Rock EM, Bolognini D, Limebeer CL, et al. Cannabidiol, a non-psychotropic component of cannabis, attenuates vomiting and nausea-like behaviour via indirect agonism of 5-HT(1A) somatodentritic utoreceptors in the dorsal raphe nucleus. Br J Pharmacol. 2012;165:2620-2634.

64. Rock EM, Limebeer CL, Ward J, et al. Interference with acute nausea and anticipatory nausea in rats by fatty acid amide hydrolase (FAAH) inhibition through a PPAR $\alpha$ and CB1 receptor mechanism, respectively: a double dissociation. Psychopharmacology (Berl). 2015;232:3841-3848.

65. Ahn K, Johnson DS, Mileni M, et al. Discovery and characterization of a highly selective FAAH inhibitor that reduces inflammatory pain. Chem Biol. 2009;16:411-420.

66. Cross-Mellor SK, Ossenkopp KP, Piomelli D, et al. Effects of the FAAH inhibitor, URB597, and anandamide on lithium-induced taste reactivity responses: a measure of nausea in the rat. Psychopharmacology (Berl). 2007;190:135-143.

67. Sticht MA, Long JZ, Rock EM, et al. Inhibition of monoacylglycerol lipase attenuates vomiting in Suncus murinus and 2-arachidonoyl glycerol attenuates nausea in rats. Br J Pharmacol. 2012;165:2425-2435.

68. Parker LA, Niphakis MJ, Downey R, et al. Effect of selective inhibition of monoacylglycerol lipase (MAGL) on acute nausea, anticipatory nausea, and vomiting in rats and Suncus murinus. Psychopharmacology (Berl). 2015;232:583-593.

69. Penfield W, Faulk ME. The insula: further observations on its function Brain. 1955;78:445-470.

70. Catenoix $\mathrm{H}$, Isnard J, Guénot $\mathrm{M}$, et al. The role of the anterior insular cortex in ictal vomiting: a stereotactic electroencephalography study. Epilepsy Behav. 2008;13:560-563.

71. Isnard J, Guénot M, Sindou M, et al. Clinical manifestations of insular lobe seizures: a stereo-electroencephalographic study. Epilepsia. 2004:45:1079-1090.

72. Ostrowsky K, Isnard J, Ryvlin P, et al. Functional mapping of the insular cortex: clinical implication in temporal lobe epilepsy. Epilepsia. 2000;41:681-686.

73. Napadow V, Sheehan JD, Kim J, et al. The brain circuitry underlying the temporal evolution of nausea in humans. Cereb Cortex. 2013;23:806-813. 
74. Sclocco R, Kim J, Garcia RG, et al. Brain circuitry supporting multi-organ autonomic outflow in response to nausea. Cereb Cortex. 2014;26:485-497.

75. Limebeer CL, Rock EM, Mechoulam R, et al. The anti-nausea effects of CB1 agonists are mediated by an action at the visceral insular cortex. $\mathrm{Br}$ J Pharmacol. 2012;167:1126-1136.

76. Sticht MA, Limebeer C., Rafla B, et al. Endocannabinoid regulation of nausea is mediated by 2-arachidonoylglycerol (2-AG) in the rat visceral insular cortex. Neuropharmacology. 2016;102:92-102.

77. Limebeer CL, Krohn JP, Cross-Mellor S, et al. Exposure to a context previously associated with nausea elicits conditioned gaping in rats: a model of anticipatory nausea. Behav Brain Res. 2008;187:33-40.

78. Limebeer CL, Hall G, Parker LA. Exposure to a lithium-paired context elicits gaping in rats: a model of anticipatory nausea. Physiol Behav. 2006;88:398-403.

79. Rock EM, Limebeer CL, Navaratnam R, et al. A comparison of cannabidiolic acid with other treatments for anticipatory nausea using a rat model of contextually elicited conditioned gaping. Psychopharmacology (Berl). 2014;231:3207-3215.

80. Rock EM, Limebeer $\mathrm{CL}$, Mechoulam R, et al. The effect of cannabidiol and URB597 on conditioned gaping (a model of nausea) elicited by a lithiumpaired context in the rat. Psychopharmacology (Berl). 2008;196:389-395.

81. Parker LA, Rock EM, Sticht MA, et al. Cannabinoids suppress acute and anticipatory nausea in pre-clinical rat models of conditioned gaping. Clin Pharmacol Ther. 2015;97:559-561.

82. Limebeer CL, Abdullah RA, Rock EM, et al. Attenuation of anticipatory nausea in a rat model of contextually elicited conditioned gaping by enhancement of the endocannabinoid system. Psychopharmacology (Berl). 2014;231:603-612.
83. Limebeer $\mathrm{CL}$, Rock EM, Puvanenthirarajah $\mathrm{N}$, et al. Elevation of 2-AG by monoacylglycerol lipase inhibition in the visceral insular cortex interferes with anticipatory nausea in a rat model. Behav Neurosci. 2016;130:261-266.

Cite this article as: Rock EM, Sticht MA, Limebeer CL, Parker LA (2016)

Cannabinoid regulation of acute and anticipatory nausea, Cannabis and Cannabinoid Research 1:1, 113-121, DOI: 10.1089/can.2016.0006.

\section{Abbreviations Used}

$2-\mathrm{AG}=2$-arachidonylglyercol

$5-\mathrm{HT}_{3}=5$-hydroxytryptamine 3

$\mathrm{AEA}=$ anandamide

$\mathrm{CB}_{1}=$ cannabinoid 1

$\mathrm{CBD}=$ cannabidiol

CBDA = cannabidiolic acid

$\mathrm{FAAH}=$ fatty acid amide hydrolase

$\mathrm{IC}=$ insular cortex

$\mathrm{LiCl}=$ lithium chloride

MAGL $=$ monoacylglycerol lipase

NK-1 = neurokinin-1

OEA $=$ oleoylethanolamide

$\mathrm{PEA}=$ palmitoylethanolamide

$\mathrm{THC}=$ delta-9-tetrahydrocannabinol

\section{Publish in Cannabis and Cannabinoid Research}

Cannabis and

Cannabinoid

Research
- Immediate, unrestricted online access

- Rigorous peer review

- Compliance with open access mandates

- Authors retain copyright

- Highly indexed

- Targeted email marketing 